\title{
Survival of invasive bladder cancer patients, 1998-2009; a central and northern Denmark population-based cohort study
}

This article was published in the following Dove Press journal:

Clinical Epidemiology

19 July 2011

Number of times this article has been viewed

\section{Lars Lund ${ }^{1,2}$ \\ R Erichsen' \\ $M$ Nørgaard' \\ E H Larsen ${ }^{3}$ \\ M Borre ${ }^{4}$ \\ J Jacobsen'}

'Department of Clinical Epidemiology, Aarhus University Hospital, Denmark; ${ }^{2}$ Department of Urology, Viborg Hospital, Denmark; ${ }^{3}$ Department of Urology, Aarhus University Hospital, Aalborg, Denmark; ${ }^{4}$ Department of Urology, Aarhus University Hospital, Skejby, Denmark
Correspondence: Lars Lund Department of Urology, Viborg Hospital, Heibergs alle 4, 8800 Viborg, Denmark Email lars.lund@viborg.rm.dk
Objective: Invasive bladder cancer (IBC) is a common urological malignancy accounting for $4 \%-5 \%$ of all cancers in Denmark. Our aim was to examine possible changes in short- and long-term survival of patients with IBC during 1998-2009.

Study design and setting: Data on all patients $(\mathrm{N}=4032)$ with an incident diagnosis of IBC within a population of 1.8 million were retrieved from the Danish National Registry of Patients from 1998 to 2009. We computed survival after 1, 3, and 5 years, stratified by age and gender, and estimated mortality rate ratios (MRR) using Cox proportional hazard regression to compare mortality over time, controlling for age and gender. Data on tumor stage or histology were not included.

Results: During the study period, the annual numbers of incident IBC patients remained stable. The median age was 74 years in each of the four 3-year periods in the study. The survival was relatively stable during the first three periods, whilst data from the last period showed modest improvement. The overall 1-year survival increased from 68\% in 1998-2000 to 70\% in 2007-2009, corresponding to an age and gender adjusted MRR of 0.89 (95\% confidence interval $[\mathrm{CI}] 0.76-1.03$ ). The 3 - and 5-year survival was predicted to increase from $44 \%$ to $49 \%$ and from $35 \%$ to $40 \%$ respectively. This corresponded to a 3 -year age and gender adjusted MRR of 0.87 (95\% CI 0.77-0.98) and a 5-year MRR of 0.88 (95\% CI 0.79-0.99). The 1-, 3-, and 5-year survival increased for men in all age groups ( $<70$ years, 70-79 years, $\geq 80$ years) and in women only in the 70-79-year age group.

Conclusion: The survival of IBC patients increased slightly in northern and central Denmark in the 1998-2009 period.

Keywords: outcome research, MRR, mortality rate ratio

\section{Introduction}

Bladder cancer is the fourth most common cancer in men and ninth most common cancer in women, with 68,000 new cases and 14,000 deaths estimated in the United States in 2008. ${ }^{1}$ In Denmark, the annual incidence was $27 / 100,000$ in 2009 thereby accounting for $4 \%-5 \%$ of all cancers. ${ }^{2}$ A number of studies have reported that the prognosis after early stage (Ta, T1) bladder cancer is good, ${ }^{3-7}$ with a 5 -year survival exceeding $75 \%{ }^{7}$ However, we have previously shown that the overall 1-year survival following bladder cancer in a Danish regional population-based setting, including both early and late stage cancers, was only around $65 \%$ and 5 -year survival was around $35 \% .{ }^{8}$ Of major concern, our previous study also showed that the survival did not improve substantially in the 1996-2007 period. Such lack of increase in survival was supported by a nationwide populationbased Danish study, which reported unchanged one-year relative (age standardized) 
survival estimates for the 1995-2006 period. ${ }^{9}$ Furthermore, the EUROCARE-4 study including cancer cases from cancer registries in 23 European countries reported that Danish bladder cancer patients diagnosed in 1995-1999 had an age-standardized 5-year relative survival of 68.9 (95\% confidence interval [CI] 67.5-70.3) compared with a 5-year relative survival of 72.4 (95\% CI 71.9-72.8) combined for the 23 countries. ${ }^{10}$ These results of a lower survival among Danish bladder cancer patients were supported by a more recent Nordic study including data through 2003. ${ }^{11}$ The reasons for a lower survival in Denmark than in other western European countries remain unknown. To improve survival for cancer in Denmark in general, the Danish government implemented National Cancer Plans in 2000 and 2005 with the aim to diagnose and treat patients with cancer at an earlier stage. ${ }^{12}$

We therefore conducted the present study to monitor survival in Danish invasive bladder cancer (IBC) patients during the period in which these plans were introduced.

\section{Materials and methods}

We conducted this study in the central and the northern Denmark regions, with a combined population of 1.8 million persons. The National Health Service provides tax-supported health care for all inhabitants of Denmark, guaranteeing free access to hospitals. In Denmark, all bladder cancer patients are seen at a hospital by a specialist in urology who takes care of their treatment. Virtually no bladder cancer patients were treated in private hospitals during the study period. The surgical and oncological treatment is centralized to only five hospitals.

\section{Identification of bladder cancer patients}

Through the Danish National Registry of Patients (DNRP), we identified all patients who had a first-time hospitalization with bladder cancer in the period January 1, 1998 through December 31, 2009. The DNRP contains information about all admissions from nonpsychiatric hospitals in Denmark since 1977. ${ }^{13}$ Outpatient and emergency room visits at hospitals have been included since 1995. This registry includes information on civil registration number, dates of admission and discharge, surgical procedure(s) performed, and up to 20 diagnoses from each hospital contact. Diagnoses have been classified according to the International Classification of Diseases 10th edition, and the code used to identify bladder cancer was C67.

\section{Follow-up}

Since 1968, the Central Office of Civil Registration has assigned a unique 10-digit personal identification number to all Danish citizens. ${ }^{14}$ This number, unique to each Danish resident, is used in all Danish registries, allowing unambiguous individual-level data linkage. From the Civil Registration System we also obtained information on vital status (dead or alive), date of death, and residence for all cancer patients.

\section{Statistical analysis}

We followed each patient from date of cancer diagnosis until emigration, death, or 25 June, 2010, whichever came first. To visualize crude survival, we constructed Kaplan-Meier curves stratified according to period of diagnosis (1998-2000, 2001-2003, 2004-2006, and 2007-2009). In the latter periods, we estimated 3- and 5-year survival using a hybrid analysis in which we included the actual survival for as long as possible and then estimated the conditional probability of surviving thereafter based on the corresponding survival experience of patients in the previous period (ie, using a period analysis technique). ${ }^{15}$ To compare mortality over time, we used Cox proportional hazards regression analysis, with 1998-2000 as the reference period to estimate 1-, 3-, and 5-year mortality rate ratios (MRRs) and corresponding 95\% CIs, adjusting for age group (15-69, 70-79, $80+$ years) and gender. Analyses were performed using SAS version 9.2 (SAS Institute Inc, Cary, NC).

\section{Results \\ Descriptive data}

We identified 4032 patients (2992 men and 1040 women) with a new diagnosis of IBC between 1998 and 2009. Median age at cancer diagnosis was 74 years (range 33-96 years). The annual number of bladder cancer patients remained stable during the study period (Table 1).

\section{Survival}

The overall 1-year survival increased slightly from $68 \%$ in 1998-2000 to $70 \%$ in 2007-2009, corresponding to an age and gender adjusted MRR of 0.89 (95\% CI 0.76-1.03) (Figure 1 and Table 1). The 3- and 5-year survival is predicted to increase from $44 \%$ to $49 \%$ and from $35 \%$ to $40 \%$, respectively. This corresponded to a 3-year age- and gender-adjusted MRR of 0.87 (95\% CI 0.77-0.98) and a 5-year MRR of 0.88 (95\% CI 0.79-0.99) in the 2007-2009 period (Table 1).

With few exceptions, particularly among the younger women, the 1-, 3-, and 5-year survival increased over the study period across age groups and gender (Tables 2 and 3). In general, men had a slightly higher 1-year survival than females. For instance, $82 \%$ of 15-69-year-old men survived 1 year after the cancer diagnosis in the 2007-2009 periods, 
Table I I-, 3-, and 5-year survival, and the crude, gender-and age-adjusted I-, 3-, and 5-year all-cause MRRs in the four time periods. The reference was patients from the period 1998-2000

\begin{tabular}{|c|c|c|c|c|}
\hline & \multicolumn{4}{|c|}{ Year of diagnosis } \\
\hline & $1998-2000$ & $200 I-2003$ & 2004-2006 & 2007-2009 \\
\hline Number of cancer patients & 1028 & 960 & 965 & 1079 \\
\hline Median age (years) & 73 & 74 & 74 & 74 \\
\hline \multicolumn{5}{|l|}{ I year } \\
\hline Survival & $68 \%(65 \%-70 \%)$ & $63 \%(60 \%-66 \%)$ & $64 \%(61 \%-67 \%)$ & $70 \%(67 \%-73 \%)$ \\
\hline MRRs & I (reference) & $1.18(1.02-1.37)$ & $1.16(0.99-1.34)$ & $0.91(0.78-1.06)$ \\
\hline Adjusted MRRs ${ }^{\mathrm{a}}$ & I (reference) & $1.17(1.01-1.36)$ & $1.16(1.00-1.34)$ & $0.89(0.76-1.03)$ \\
\hline \multicolumn{5}{|l|}{3 year } \\
\hline Survival & $44 \%(41 \%-47 \%)$ & $42 \%(39 \%-45 \%)$ & $43 \%(40 \%-46 \%)$ & $49 \%(46 \%-52 \%)^{b}$ \\
\hline MRRs & I (reference) & $1.07(0.96-1.21)$ & $1.04(0.93-1.17)$ & $0.88(0.78-0.99)^{\mathrm{b}}$ \\
\hline Adjusted MRRs ${ }^{a}$ & I (reference) & $1.07(0.95-1.20)$ & $1.05(0.94-1.18)$ & $0.87(0.77-0.98)^{\mathrm{b}}$ \\
\hline \multicolumn{5}{|l|}{5 year } \\
\hline Survival & $35 \%(32 \%-38 \%)$ & $33 \%(30 \%-36 \%)$ & $35 \%(32 \%-38 \%)^{b}$ & $40 \%(37 \%-43 \%)^{b}$ \\
\hline MRRs & I (reference) & $1.08(0.97-1.20)$ & $1.03(0.93-1.15)^{\mathrm{b}}$ & $0.89(0.80-0.99)^{\mathrm{b}}$ \\
\hline Adjusted MRRs ${ }^{a}$ & I (reference) & I.08 (0.97-I.20) & $1.05(0.94-1.17)^{\mathrm{b}}$ & $0.88(0.79-0.99)^{\mathrm{b}}$ \\
\hline
\end{tabular}

Notes: The corresponding $95 \%$ confidence intervals are given in parentheses. ${ }^{2}$ Adjusted for age and gender; 'Predicted values.

Abbreviation: MRR, mortality rate ratio.

while only $64 \%$ of women of the same age were alive after 1 year. In this younger age group, the 3-and 5-year survival was also highest in men, while the 3- and 5-year survival was virtually similar in men and women more than 70 years of age at least in the 2007-2009 periods.

\section{Discussion}

In this population-based cohort study we found that the mortality of IBC decreased by approximately $10 \%$ comparing 2007-2009 with 1998-2000. However, for women younger than 70 years of age the survival remained stable and was lower than the survival in men younger than 70 years at study end.
Several factors should be considered when interpreting our results. The validity of our results is to a large degree dependent on our ability to identify the IBC population and to the reliability of our follow-up information. Denmark has a uniformly organized public health care system that allowed for a population-based design with complete long-term follow-up for mortality. We included all admitted-patient and out-patient visits at hospitals with bladder cancer from two Danish regions in the study. Still, it is well known that the coding of hospital diagnoses may not always be accurate. However, the cancer diagnoses in the DNRP have generally been reported to have a high validity. ${ }^{16} \mathrm{~A}$ weakness of our study, however, is the absence of specific tumor pathologic

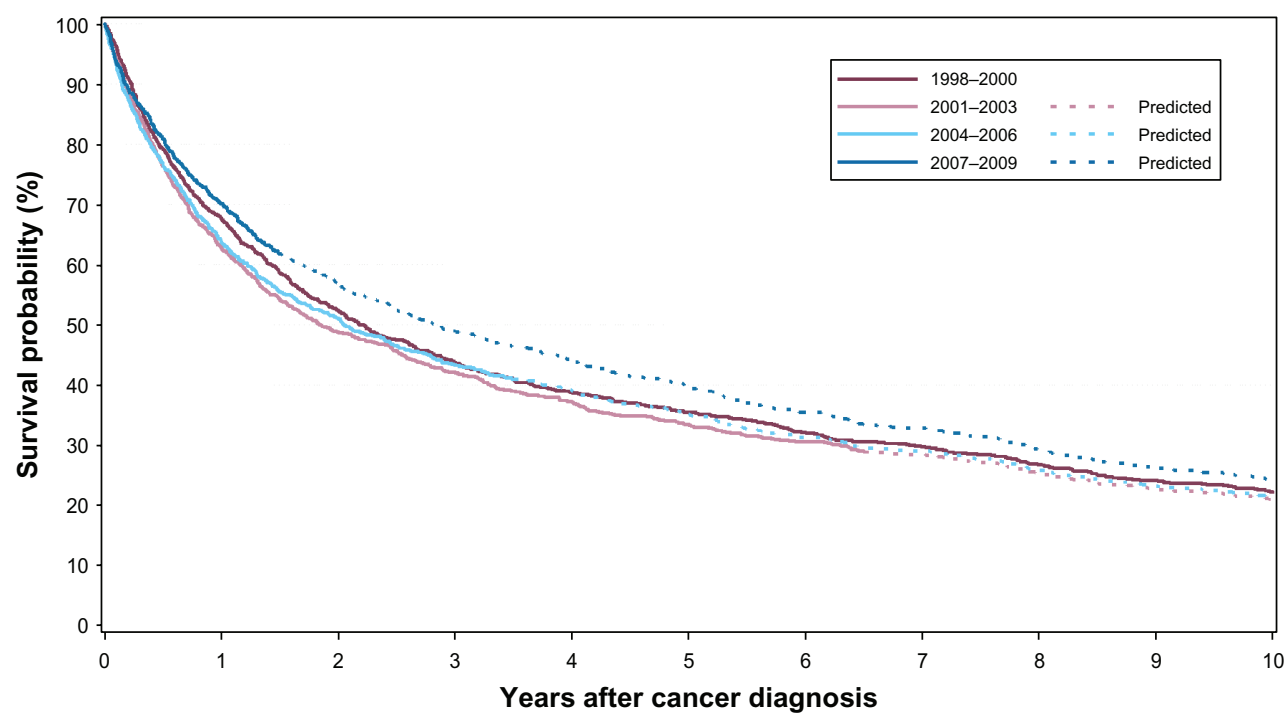

Figure I Overall survival in Danish invasive bladder cancer patients diagnosed in the period 1998-2009 in two of five Danish regions. 
Table 2 I-, 3-, and 5-year survival in men with bladder cancer in the four time periods, examined by age

\begin{tabular}{|c|c|c|c|c|}
\hline \multirow{2}{*}{$\frac{\text { Men }}{\text { Age (years) }}$} & \multicolumn{4}{|c|}{ Year of diagnosis } \\
\hline & $1998-2000$ & $200 I-2003$ & 2004-2006 & 2007-2009 \\
\hline \multicolumn{5}{|l|}{$15-69$} \\
\hline Number of cancer patients [\%] & 299 [39\%] & $252[36 \%]$ & $268[37 \%]$ & 299 [37\%] \\
\hline I-year survival & $78 \%(73 \%-82 \%)$ & $79 \%(73 \%-84 \%)$ & $85 \%(80 \%-88 \%)$ & $82 \%(77 \%-86 \%)$ \\
\hline 3-year survival & $61 \%(55 \%-66 \%)$ & $60 \%(54 \%-66 \%)$ & $67 \%(61 \%-72 \%)$ & $67 \%(61 \%-72 \%)^{a}$ \\
\hline 5-year survival & $55 \%(49 \%-60 \%)$ & $52 \%(46 \%-58 \%)$ & $58 \%(52 \%-64 \%)^{\mathrm{a}}$ & $57 \%(51 \%-63 \%)^{\mathrm{a}}$ \\
\hline \multicolumn{5}{|l|}{ 70-79 } \\
\hline Number of cancer patients [\%] & $293[38 \%]$ & 258 [37\%] & 275 [38\%] & 298 [37\%] \\
\hline I-year survival & $74 \%(69 \%-79 \%)$ & $66 \%(60 \%-72 \%)$ & $65 \%(59 \%-70 \%)$ & $77 \%(72 \%-82 \%)$ \\
\hline 3-year survival & $46 \%(40 \%-52 \%)$ & $45 \%(39 \%-51 \%)$ & $42 \%(36 \%-48 \%)$ & $48 \%(42 \%-54 \%)^{\mathrm{a}}$ \\
\hline 5-year survival & $33 \%(28 \%-39 \%)$ & $36 \%(30 \%-41 \%)$ & $34 \%(29 \%-40 \%)^{\mathrm{a}}$ & $39 \%(33 \%-45 \%)^{\mathrm{a}}$ \\
\hline \multicolumn{5}{|l|}{$80+$} \\
\hline Number of cancer patients [\%] & $|8|[23 \%]$ & $182[26 \%]$ & $186[26 \%]$ & 201 [26\%] \\
\hline I-year survival & $51 \%(44 \%-58 \%)$ & $48 \%(40 \%-55 \%)$ & $45 \%(37 \%-52 \%)$ & $57 \%(50 \%-63 \%)$ \\
\hline 3-year survival & $25 \%(19 \%-31 \%)$ & $24 \%(18 \%-30 \%)$ & $22 \%(16 \%-28 \%)$ & $30 \%(24 \%-37 \%)^{\mathrm{a}}$ \\
\hline 5-year survival & $15 \%(\mid 1 \%-21 \%)$ & $14 \%(10 \%-20 \%)$ & $14 \%(9 \%-19 \%)^{a}$ & $19 \%(13 \%-26 \%)^{\mathrm{a}}$ \\
\hline
\end{tabular}

Notes: The corresponding $95 \%$ confidence interval is given in parentheses. aPredicted values.

data such as histological pattern of tissue differentiation and tumor stage. Thus, we were unable to evaluate whether the improvement in survival stemmed from changes over the study period in any of these factors. Nevertheless, if improved diagnostic techniques over time have resulted in changes in stage classification (ie, stage migration) stage-specific survival could be biased. ${ }^{17}$ On the other hand, changes in stage distribution may be part of the causal pathway to improved survival over time, and if so, adjustment for stage could be inappropriate. However, results from the Danish Bladder Cancer Registry Group's yearly report, ${ }^{18}$ which is based on detailed data from the Danish Pathology Registry, have shown that neither cancer histology nor cancer stage has changed substantially over the study period.
In a previous study from our region, we found that survival in IBC patients had not appreciably altered in Denmark in the 1995-2004 period. ${ }^{8}$ The newly implemented National Cancer Plan ${ }^{12}$ was initiated to improve health care organization including faster and easier availability of diagnostic follow-up and treatment. Accordingly, cancer surgery, chemotherapy, and radiation have been centralized to fewer specialized centers. Furthermore, new diagnostic procedures such as photodynamic procedures have been implemented, and the surgical techniques have become less invasive with better equipment and instruments. ${ }^{19}$ Recent nationwide data from the USA in the period 2003-2007 including 40,388 patients with IBC confirmed improvements in process of care measures in patients who underwent cystectomy. ${ }^{20}$

Table 3 I-, 3-, and 5-year survival in women with bladder cancer in the four time periods, examined by age

\begin{tabular}{|c|c|c|c|c|}
\hline \multirow{2}{*}{$\frac{\text { Women }}{\text { Age (years) }}$} & \multicolumn{4}{|c|}{ Year of diagnosis } \\
\hline & $1998-2000$ & $200 I-2003$ & 2004-2006 & 2007-2009 \\
\hline \multicolumn{5}{|l|}{$15-69$} \\
\hline Number of cancer patients [\%] & $98[38 \%]$ & $102[38 \%]$ & $83[35 \%]$ & $88[31 \%]$ \\
\hline I-year survival & $68 \%(58 \%-77 \%)$ & $70 \%(60 \%-78 \%)$ & $65 \%(54 \%-74 \%)$ & $64 \%(53 \%-74 \%)$ \\
\hline 3-year survival & $44 \%(34 \%-53 \%)$ & $48 \%(38 \%-57 \%)$ & $45 \%(34 \%-55 \%)$ & $42 \%(31 \%-52 \%)^{a}$ \\
\hline 5-year survival & $42 \%(32 \%-51 \%)$ & $40 \%(30 \%-49 \%)$ & $39 \%(29 \%-50 \%)^{\mathrm{a}}$ & $37 \%(27 \%-47 \%)^{a}$ \\
\hline \multicolumn{5}{|l|}{ 70-79 } \\
\hline Number of cancer patients [\%] & 87 [34\%] & 95 [35\%] & 83 [35\%] & $106[38 \%]$ \\
\hline I-year survival & $56 \%(45 \%-66 \%)$ & $55 \%(44 \%-64 \%)$ & $60 \%(49 \%-70 \%)$ & $72 \%(62 \%-80 \%)$ \\
\hline 3-year survival & $31 \%(22 \%-41 \%)$ & $39 \%(29 \%-49 \%)$ & $42 \%(31 \%-52 \%)$ & $52 \%(42 \%-61 \%)^{\mathrm{a}}$ \\
\hline 5-year survival & $26 \%(18 \%-36 \%)$ & $28 \%(20 \%-38 \%)$ & $32 \%(22 \%-42 \%)^{a}$ & $40 \%(29 \%-50 \%)^{\mathrm{a}}$ \\
\hline \multicolumn{5}{|l|}{$80+$} \\
\hline Number of cancer patients [\%] & $70[27 \%]$ & $71[26 \%]$ & $70[30 \%]$ & 87 [31\%] \\
\hline I-year survival & $49 \%(36 \%-60 \%)$ & $31 \%(21 \%-42 \%)$ & $30 \%(20 \%-41 \%)$ & $43 \%(33 \%-54 \%)$ \\
\hline 3-year survival & $24 \%(15 \%-35 \%)$ & $8 \%(3 \%-16 \%)$ & $14 \%(7 \%-23 \%)$ & $31 \%(20 \%-42 \%)^{a}$ \\
\hline 5-year survival & $17 \%(9 \%-27 \%)$ & $4 \%(1 \%-11 \%)$ & $7 \%(2 \%-17 \%)^{a}$ & $18 \%(5 \%-36 \%)^{\mathrm{a}}$ \\
\hline
\end{tabular}

Notes: The corresponding $95 \%$ confidence interval is given in parentheses. ${ }^{\text {PPredicted values. }}$ 
The proportion of patients treated with cystectomy (42.9\%) and radiation therapy (16.6\%) remained stable with time, while the proportion of those who received chemotherapy increased from $27.0 \%$ in 2003 to $34.5 \%$ in $2007 .^{20}$

The improvement in survival, irrespective of gender, among patients aged $70+$ years could partly be due to a change in life expectancy in the Danish population during the study period. In the two nationwide studies, ${ }^{9,11}$ which included Danish data and reported relative survival estimates (relative to the background population), the survival seemed not to improve in the most recent years, indicating that it may be the general life expectancy more than a specific improvement in bladder cancer survival that caused the observed increase in survival in our study. However, these studies only included data through $2003^{11}$ and $2006,{ }^{9}$ respectively, and we only observed the survival improvement in the later 2007-2009 period. In addition, we also find it unlikely that the life expectancy has increased substantially within just a few years. Therefore, although we cannot rule out completely that changes in life expectancy had influence on our estimates, we find it unlikely that this was the main explanation.

In conclusion, our study showed that the survival of IBC patients increased slightly in northern and central Denmark in the 1998-2009 period.

\section{Financial support}

The study received financial support from the Karen Elise Jensen Foundation, Department of Clinical Epidemiology's Research Foundation and the Regional Clinical Epidemiological Monitoring Initiative for Central and North Denmark Regions.

\section{Disclosure}

The authors report no conflicts of interest in this work.

\section{References}

1. Jemal A, Bray F, Center MM, Ferlay J, Ward E, Forman D. Global cancer statistics. CA Cancer J Clin. 2011;61:69-90.

2. Sundhedsstyrelsen. Cancerregisteret. 2009. http://www.sst.dk/publ/ Publ2010/DOKU/Registre/Cancerregisteret2009.pdf. Accessed May 23, 2011

3. Nishiyama H, Habuchi T, Watanabe J, et al. Clinical outcome of a largescale multi-institutional retrospective study for locally advanced bladder cancer: a survey including 1131 patients treated during 1990-2000 in Japan. Eur Urol. 2004;45:176-181.

Clinical Epidemiology

\section{Publish your work in this journal}

Clinical Epidemiology is an international, peer-reviewed, open access journal focusing on disease and drug epidemiology, identification of risk factors and screening procedures to develop optimal preventative initiatives and programs. Specific topics include: diagnosis, prognosis, treatment, screening, prevention, risk factor modification, systematic
4. Gardmark T, Bladstrom A, Hellsten S, Malmstrom PU; for Members of the Swedish National Bladder Cancer Registry. Analysis of clinical characteristics, management and survival of patients with Ta T1 bladder tumours in Sweden between 1997 and 2001. Scand J Urol Nephrol. 2006;40:276-282.

5. Holmang S, Hedelin H, Anderstrom C, Johansson SL. The relationship among multiple recurrences, progression and prognosis of patients with stages Ta and T1 transitional cell cancer of the bladder followed for at least 20 years. $J$ Urol. 1995;153:1823-1827.

6. Gschwend JE, Dahm P, Fair WR. Disease specific survival as endpoint of outcome for bladder cancer patients following radical cystectomy. Eur Urol. 2002;41:440-448.

7. Larsson $\mathrm{P}$, Wijkstrom H, Thorstenson A, et al. A population-based study of 538 patients with newly detected urinary bladder neoplasms followed during 5 years. Scand J Urol Nephrol. 2003;37:195-201.

8. Lund L, Jacobsen J, Clark PE, Sorensen HT, Nørgaard M. The impact of comorbidity on survival of invasive bladder cancer patients; 1995-2004; a Danish population-based cohort study. Urology. 2010;76: 393-398.

9. Storm HH, Gislum M, Kejs AM, Engholm G. Survival of Danish cancer patients 1995-2006. Ugeskr Laeger. 2010;172:2213-2217.

10. Sant M, Allemani C, Santaquilani M, Knijn A, Marchesi F, Capocaccia R; for the EUROCARE Working Group. EUROCARE-4. Survival of cancer patients diagnosed in 1995-1999. Results and commentary. Eur J Cancer. 2009;45:931-991.

11. Engholm G, Hakulinen T, Gislum M, et al. Trends in the survival of patients diagnosed with kidney or urinary bladder cancer in the Nordic countries 1964-2003 followed up to the end of 2006. Acta Oncol. 2010; 49:655-664.

12. The National Board of Health. Cancer Treatment Plans in Denmark [in Danish]. Available from: http://www.sst.dk/Udgivelser/2004. Accessed May 16, 2011.

13. Andersen TF, Madsen M, Jorgensen J, Mellemkjoer L, Olsen JH. The Danish National Hospital Register. A valuable source of data for modern health sciences. Dan Med Bull. 1999;46:263-268.

14. Pedersen CB, Gotzsche H, Moller JO, Mortensen PB. The Danish Civil Registration System. A cohort of eight million persons. Dan Med Bull. 2006;53:441-449.

15. Brenner H, Rachet B. Hybrid analysis for up-to-date long-term survival rates in cancer registries with delayed recording of incident cases. Eur J Cancer. 2004;40:2491-2501.

16. Sorensen HT. Regional administrative health registers as a resource in clinical epidemiology. A study of options, strengths, limitations and data quality provided with examples of use. Int J Risk Safety Med. 1997; $10: 1-22$

17. Feinstein AR, Sosin DM, Wells CK. The Will Rogers phenomenon. Stage migration and new diagnostic techniques as a source of misleading statistics for survival in cancer. N Engl J Med. 1985;312:1604-1608.

18. The 2008 report from the Danish Bladder Cancer Registry: Bladder tumors in Denmark, 2000-2008 [in Danish]. Available from: http:// www.ducg.dk/files/2008-DBCRyearreport2010.pdf. Accessed May 17, 2011.

19. Jocham D, Stepp H, Waidelich R. Photodynamic diagnosis in urology: state-of-the-art. Eur Urol. 2008;53:1138-1148.

20. Fedeli U, Fedewa SA, Ward EM. Treatment of muscle invasive bladder cancer: evidence from the National Cancer Database, 2003 to 2007. J Urol. 2011;185:72-78.

\section{Dovepress}

reviews, risk \& safety of medical interventions, epidemiology \& biostatical methods, evaluation of guidelines, translational medicine, health policies \& economic evaluations. The manuscript management system is completely online and includes a very quick and fair peer-review system, which is all easy to use. 